\title{
Application Six Sigma Method in Green Leaf Threshing Tobacco Plant
}

\author{
Dian Wahyu Adriyanti ${ }^{1}$, and Iwan Vanany ${ }^{2}$
}

\begin{abstract}
Green Leaf Threshing (GLT) plant is an upstream company from the tobacco industries. The GLT main processing is separate the lamina from the stem and also dry out the tobacco into safe storage moisture content. One of the problems in the GLT factory is the high frequency of refeed / rework / reprocess on defective products. High refeed frequency increases production costs and eliminates customer trust. The aim of this study is to reduce refeed frequency. Six sigma is a methodology that can be used widely in manufacturing companies and services for continuous quality improvement. The Six sigma DMAI framework is used to find out the problems and solutions. The root cause of refeed are determined using fish bone diagrams and 5 Whys tool. The ranks for improvement are determined from the RPN using FMEA Analysis. The suggested program for improvement are investing tool, repairing tool and training worker. The results of identification indicate that defects due to inappropriateness moisture content are the highest cause of refeed. The results of the improvement indicate an increaseing sigma level from 3.72 to 3,97. The DPMO also declined from 13,220 to 6,823 . Increasing sigma levelprovides benefit of Rp. 20.530.760.
\end{abstract}

Keywords-GLT Tobacco, Moisture Content, Six Sigma, FMEA.

\section{INTRODUCTION}

GLT stand from Green Leaf Threshing Tobacco are the plant where is tobacco processed and dried after purchasing from farmers into semi-finished goods for the cigarette industry supply. The processing of tobacco in GLT are mixing tobacco leaves (blending), separating tobacco leaves (lamina) from their leaf bones (Steam) (threshing) and re-drying tobacco leaves (re-drying). The quality problem that is often faced by the GLT plant is the high frequency of re-feed/rework/reprocess. Re-feed process occurs because processed tobacco products are not full fill the requirement of customer's quality specifications. Tobacco leaf must be reprocessed to achieve quality base on specifications. The re-feed frequency is directly proportional to the amount of defective products produced. Re-feed problems are quality problems that have a negative impact to the company. The negative effects are the extension of process time over initial scheduling;

\footnotetext{
${ }^{1}$ Dian Wahyu Adriyanti is postgraduate student at Department of Bussines and Management Technology, Institut Teknologi Sepuluh Nopember, Surabaya, Indonesia. E-mail: dwadriyanti@gmail.com.

${ }^{2}$ Iwan Vanany is with Department of Industrial Engineering, Institut Teknologi Sepuluh Nopember, Surabaya, Indonesia. E-mail: vanany@ie.its.ac.id.
}

increasing costs for labor overtime wages and the worst impact is the loss of customers and payment of penalties on customers. The aims of this study are to reduce re-feed frequencies using the Six Sigma methodology approach.

Six sigma is a philosophy for improving quality throughout the company. The Six Sigma approach has been widely adopted in the manufacturing sector and services to improve productivity and quality of performance[1]. Six sigma was originally developed by Motorola and then popularized by General Electric. Several other leading companies such as Honeywell, ABB, Honda, American Express and Ford also applied the Six Sigma concept. Six sigma has been regarded as a systematic and powerful technique for the process of continuous improvement and new product development using analytical tools and statistical methods[2]. Jacobs, Chase, and Aquilano (2006) define Six Sigma as a statistical term to describe the purpose of the quality of no more than four defects in one million units[3]. Size and statistics are key ingredients of Six Sigma improvement or continues improvement, but that is not the overall determinant. According to Snee in Maheswar (2012)[4]. Six Sigma is an approach to increasing business that seeks to find and eliminate defects in business processes by focusing on process output that is very important for customers. Six sigma is about producing less than 3.4 million defective parts (parts per million, PPM) which is equivalent to the results of 99.99966\%[4].

The widely used Six Sigma methodology is known as DMAIC. DMAIC is an acronym for Define-MeasureAnalyze-Improve-Control. According to Harry and Schroder in Su et al (2006) DMAIC offers the discipline and structure of methodologies to solve business problems and enable businesses to achieve a very low nonconformance leve[5]. Several Six Sigma tools in recent years have been widely used to conduct quality improvement programs. The commonly tools used in the Six Sigma method are flowcharts, run charts, Pareto diagrams, histograms, check sheet, cause and effect diagrams and control charts[3]. DMAIC methodology with tools flowchart, Pareto diagram, cause effect diagram, failure mode and effect analysis (FMEA) and 5S are used by Maheswar (2012) to apply Six Sigma to small food factories in India[4]. Widiyawati and Assyahlafi (2017) conducted research on product quality control to improve productivity using Six sigma method in a cigarette company. The causes factors that most influence for nonconformance product are known through DMAIC 
analysis. Standard Operation Process and inspection sheet were created to solve problem and improved process[6]. The Six Sigma methodology approach was also used by Santoso et al (2013) to improve the quality of Sigaret Kretek Tangan (SKT) to compete with Sigaret Kretek Mesin (SKM). Re-design and crate new design for leveling distribution tobacco tool were applied for improvement[7]. While the application of six sigma has successfully implemented in many tobacco industry, GLT plant will also using Six sigma method integrated with FMEA to improved quality.

\section{LITERATURE REVIEW}

The research was taken place in GLT plant in Sidoarjo, East Java - Indonesia. The research will be conducted in several stages as discrabeb in following Figure 1. There are four stages in this implementation. Which are Define, Measure, Analyze and Improve.These steps will be explained and discussed in the following sections.



Figure 1. Research Stage

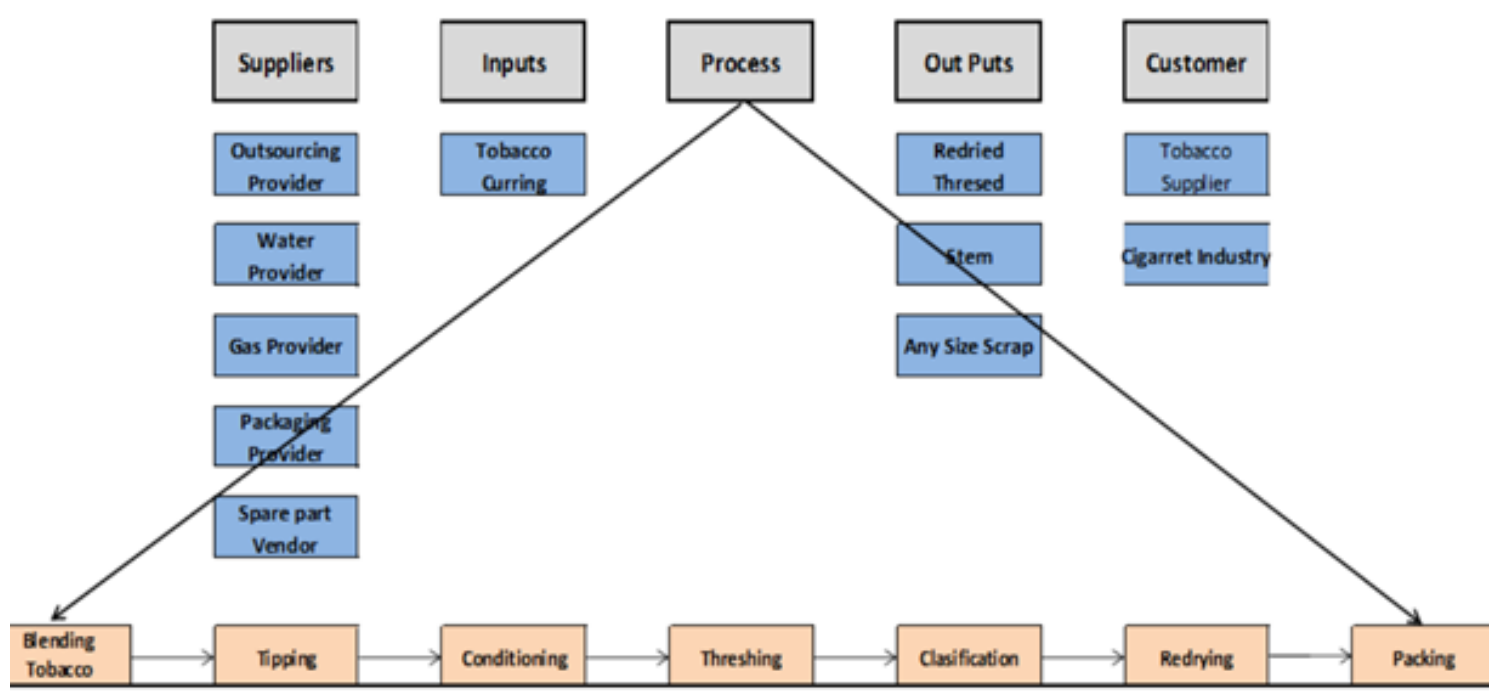

Figure 2. SIPOC Diagram 
The $1^{\text {st }}$ International Conference on Business and Management of Technology (IConBMT)

August 3rd 2019, Institut Teknologi Sepuluh Nopember, Surabaya, Indonesia

\section{RESULT AND DISCUSSION}

\section{A. Define Stage}

The firstly stage of Define is to create Project Chapter to clarify the scope of the study, the purpose and the time allocation needed. After the project chapter is created, the subsequent steps then are established SIPOC (Supplier Input Process Output Customer) diagram. The SIPOC diagram is used to help the team brainstorm and assess the processing process to find all process parameters relevant to the improvement effort before the entire research project goes further. The SIPOC diagram on the GLT plant is presented in Figure 2. In a GLT plant, different grades of tobacco are blended at the feeding table and it is namely blending step. Next step is tipping step, where the tip portion of the tobacco leaves are cut and separated, and not sent for threshing. The leaves are conditioned to high moisture by adding steam, hot air and water, to open the pads and make the leaves more pliable for better threshing at conditioning step. The conditioned leaf is equally divided and fed into a series of and it called threshing step. Threshing and classifications are repeated several times, normally 3 to 4 round. Then threshed lamina are dried in re-drying step. The dried lamina is packed at packaging step.

The quality characteristics or Critical to Quality (CTQ) are determined based on the SIPOC diagram. The CTQ for GLT plant is moisture content, tobacco's color, tobacco's flavor and stem content in lamina.

The defect type that give contributions to highly re-feed frequency during the period 2018 to February 2019 are presented in Table 1. Based on these data it can be concluded that the biggest cause of re-feed is caused by moisture defects. For that reason, moisture defects will be discussed in the next sub-section to find the root causes and solutions of these defective problems.

TABLE 1.

CONTRIBUTION TO DEFECT

\begin{tabular}{|c|c|c|c|}
\hline No & Defect Type & Defect (Packs) & Proportion \\
\hline 1 & \% Moisture & 910 & $89 \%$ \\
\hline 2 & \% PSD & $6 \%$ \\
\hline 3 & (Partikel Size Distribution) & 61 & $5 \%$ \\
\hline \% SIL & 52 & $100 \%$ \\
\hline
\end{tabular}

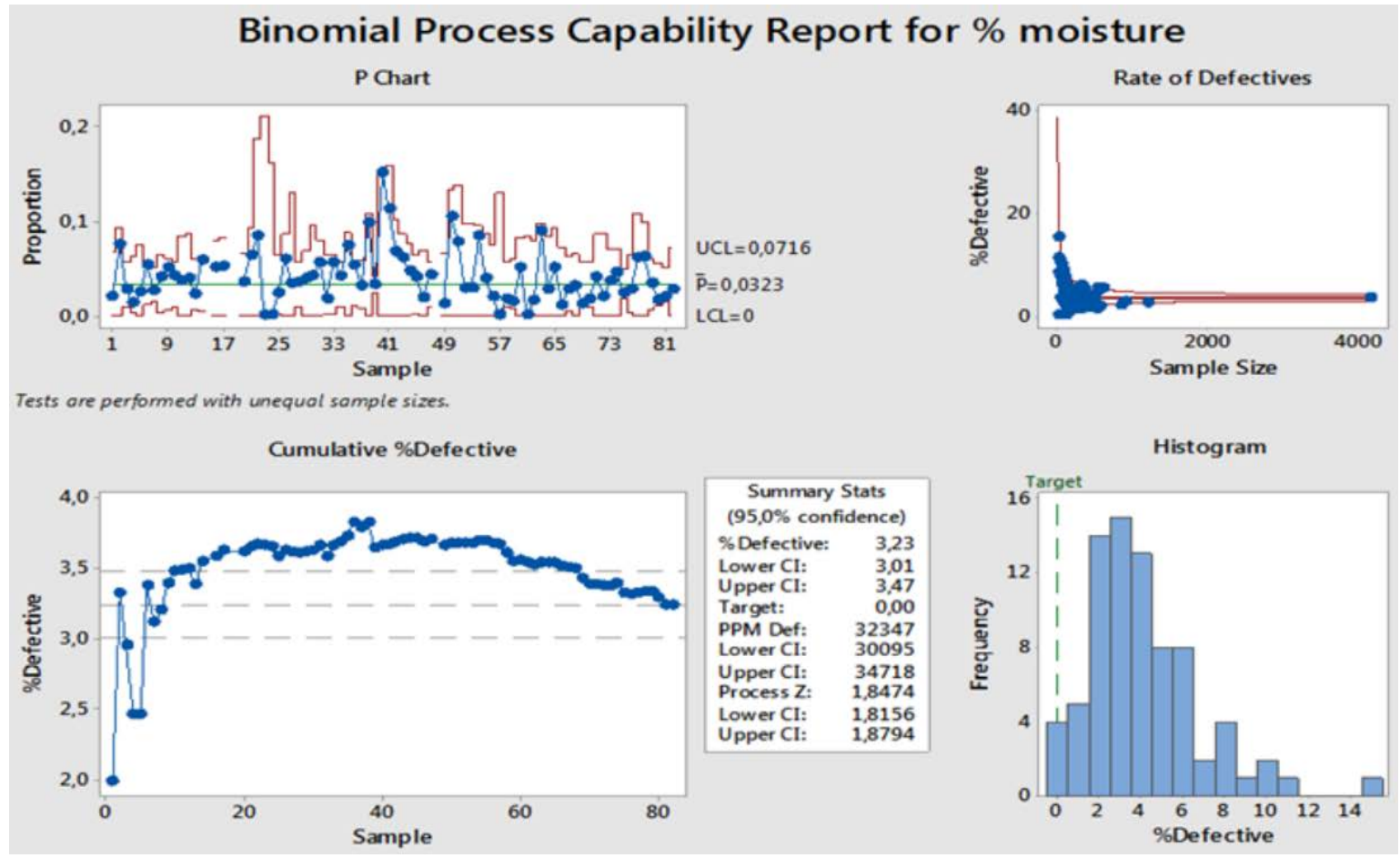

Figure 3. Capability Process Report 


\section{B. Measure Stage}

The Measure stage is conducted to calculate sigma level and process capability. The observation was conducted on 89 run processes from 2018 to February 2019. On 89 production run produce of 25,795 packs product and 1023 of them were defective products. Sigma level and DPMO were calculated using the sigma calculator program. From the calculation results obtained the sigma level for this GLT plant is 3.72 with DPMO is 132020 . The current sigma level of the company is still far from level 6 sigma. Next is measuring the current capability process capability. Capability Process is calculated through the Minitab 18 program and gives results as in Figure 3. Based on the capability process calculation, the calculated $\mathrm{Z}$ value is 1.85 while the $\mathrm{Z}$ value of the table at $95 \%$ confidence level and the 0.05 of significancy is 1.96 . The calculated $Z$ value is smaller than the $\mathrm{Z}$ table value indicating that the GLT plant's process is not capable.

\section{Analyze Stage}

Analyze stage is carried out of analysis of the causes of defect and the incapable processing in the GLT plant. Fish Bone Diagrams are diagnostic tools that show a variety of causes that contribute to the same effect or impact. Cause Effect Diagram consists of 5M and 1P: material, method, machine, measure, mother nature and people[8]. The results of brain storming are shown in the Cause Effect Diagram in Figure 4. Based on the final discussion and problem analyzed previously, focusing on the problem rather than the solution. The analysis begins with investigation of the Six Sigma team, it was decided that the six most important factors that have the greatest opportunity to influence moisture defects are as follows:

1. Information about the\% moisture is not delivered up to date (People's Criteria).

2. In proper setting of steam volume, hot air pressure and temperature heater. (People Criteria).

3. Variation of curing level raw material tobacco (Material Criteria).

4. There is no \% moisture measurement in raw tobacco material (Measurement Criteria ).

5. There is no measurement of the levelling tobacco distribution when feed on belt conveyor belt (Measurement Criteria).

6. There is no properly documentation of processing instructions (Method Criteria).

Furthermore, these factors are explored more deeply to find the root cause using the Root Causes Analysis (RCA) approach with the five whys tool. RCA will generally analyze an idea based on the making a list of problems from the system and then sorted by priority from the most important to the root of a problem can be caused. The results of five whys analysis are presented in Figure 5. The root cause of Five Whys analysis is a failure cause in FMEA analysis. Next is to suggestion solutions for improvement from the root causes of disabilities through the FMEA approach.

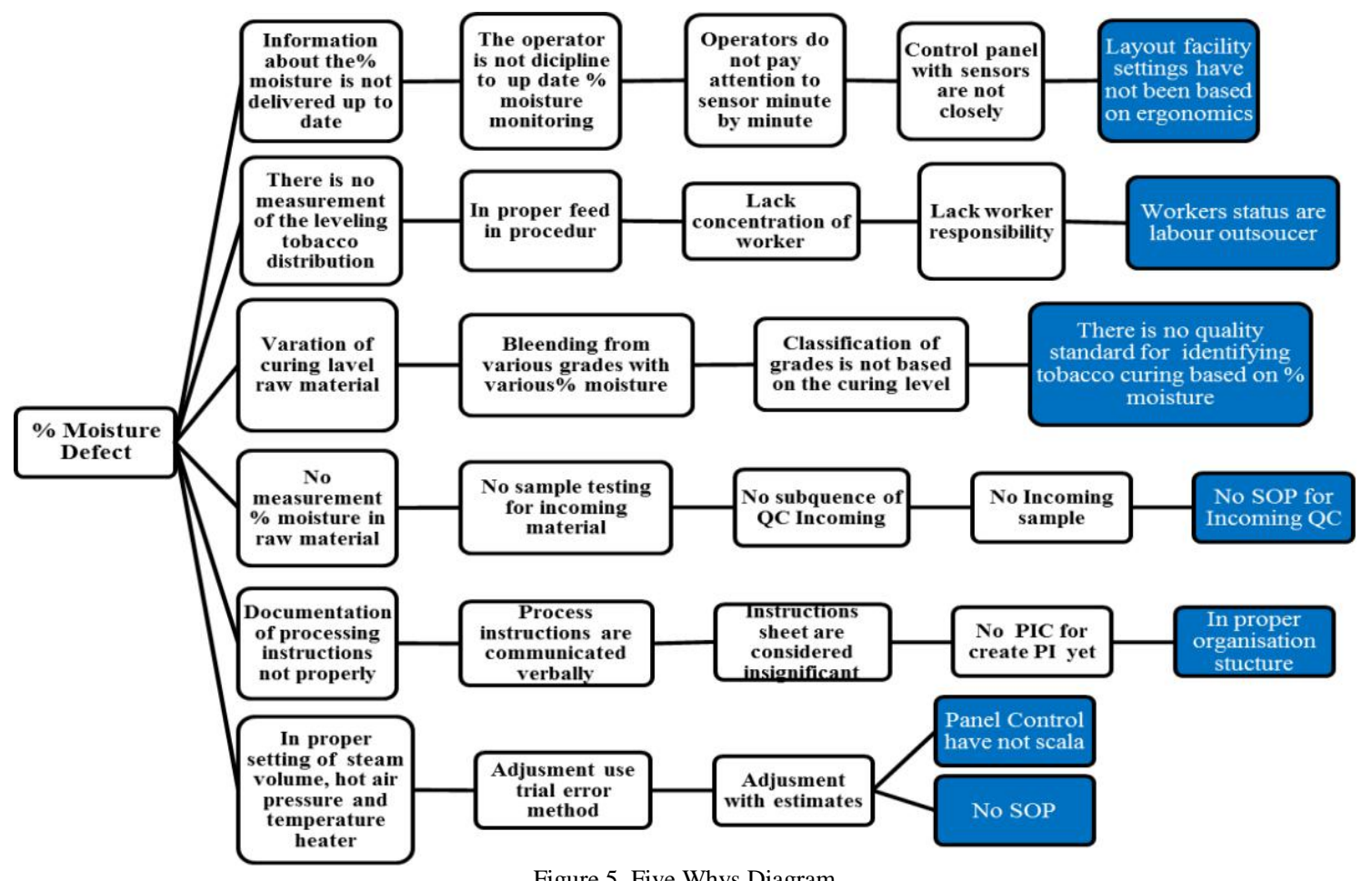

Figure 5. Five Whys Diagram 
The $1^{\text {st }}$ International Conference on Business and Management of Technology (IConBMT)

August 3rd 2019, Institut Teknologi Sepuluh Nopember, Surabaya, Indonesia

\section{Improve Stage}

Failure and Effect Analysis mode which is generally abbreviated as FMEA is a diagnostic technique that is used to detect and remove possible modes of failure, the effects caused and causes of failure [4]. The FMEA method provides a ranking of 1-10 for Severity (S), Occurrence (O) and Detection (D), those rank numbers are used to determine the potential risk value or RPN (Risk Priority Number). The value of RPN is used as a reference for improvement priorities. The higher the value of the RPN, the more attention to improvement is given. In this study rank of severity, occurrence and detection refer to the rank used by Carlson (2012)[9]. Severity value 10 is shown in $100 \%$ of finished product packs that should be re-feed and terminated in the production process. The value of RPN is calculated using the mathematics equation as follows:

$$
R P N=\text { Severity }(S) X \text { Occurance }(O) X \text { Detecbility }(D)
$$

After performing observation toward the priorities improvement through FMEA, the next step is conducting the improvement by determining solution to reduce the number of moisture defective products. The improvements solution are illustrated in Table 2. There are three category for improvement solution that are tools investment, repairing tool and training of workers. The improvement action will reduce the level of Severity (S), Occurrence and Detection (D) of each failure mode. Decreasing level of severity, occurance and detection, equally decrease the failure mode that causes the defect. If the cause of the defect can be reduced, the number of defective products produced will decrease in number. Therefore the decrease in RPN can be used to estimate reduction defect product.

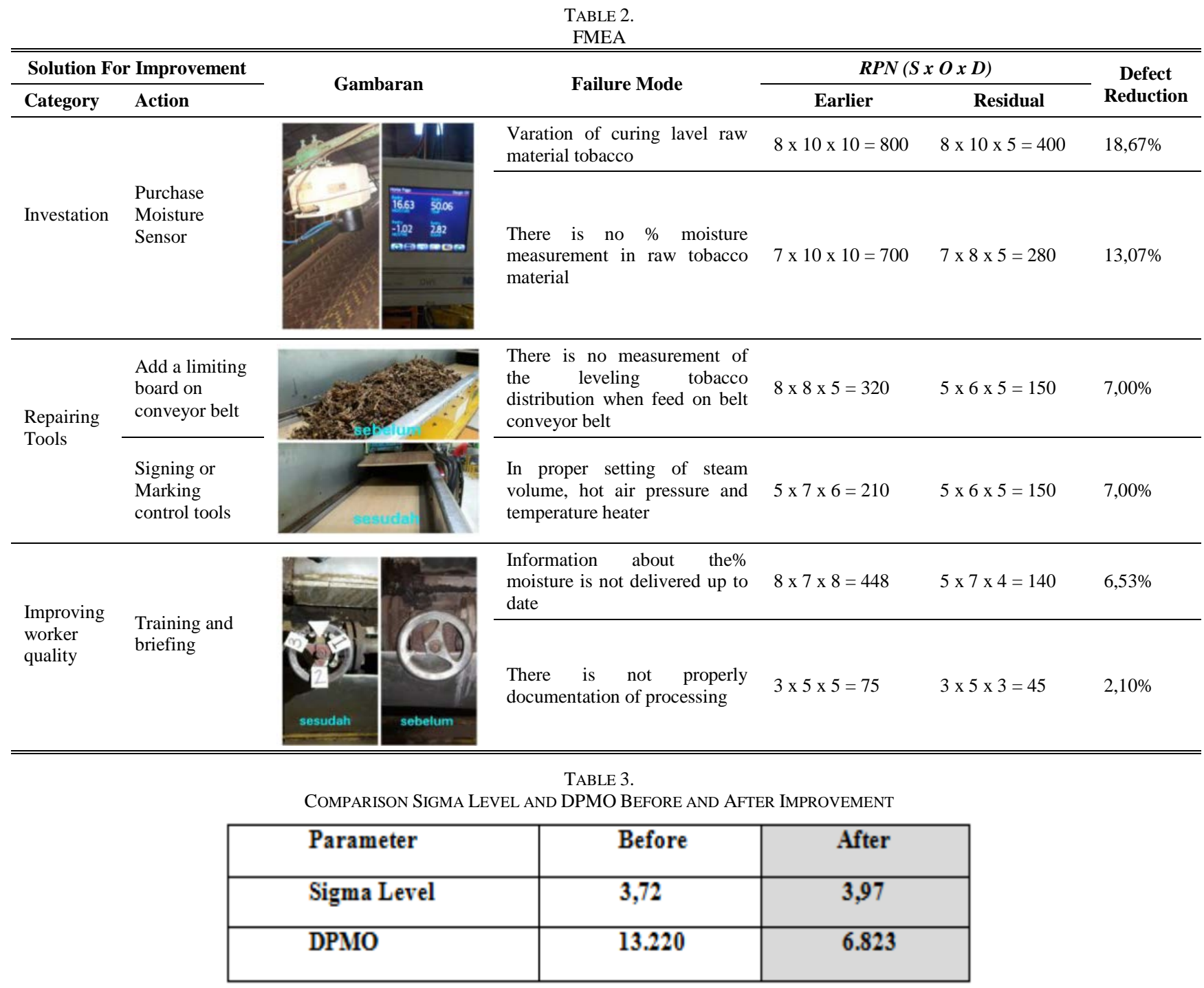


The $1^{\text {st }}$ International Conference on Business and Management of Technology (IConBMT) August 3rd 2019, Institut Teknologi Sepuluh Nopember, Surabaya, Indonesia

TABLE 4.

CALCULATION COST IMPROVEMENT, SAVING COST AND BENEFIT

\begin{tabular}{|c|c|c|c|c|c|c|c|}
\hline \multicolumn{3}{|c|}{ Improve } & \multicolumn{4}{|c|}{ Saving } & \multirow{2}{*}{ Benefit } \\
\hline Category & Cost & Cumulatif & Reduction Target & Packs Amount & Cost & Cumulatif & \\
\hline \multirow{2}{*}{ Investation } & \multirow{2}{*}{ Rp 300.000.000 } & \multirow{2}{*}{ Rp 300.000.000 } & $18,67 \%$ & 170 & Rp 112.113.535 & Rp 112.113.535 & Rp (187.886.465) \\
\hline & & & $13,07 \%$ & 119 & Rp 78.479.474 & Rp 190.593.009 & Rp (109.406.991) \\
\hline \multirow{2}{*}{$\begin{array}{l}\text { Repairing } \\
\text { Tools }\end{array}$} & \multirow[t]{2}{*}{ Rp 1.000.000 } & \multirow{2}{*}{ Rp 301.000.000 } & $7,00 \%$ & 64 & Rp 42.042.576 & Rp 232.635.584 & Rp (68.364.416) \\
\hline & & & $7,00 \%$ & 64 & Rp 42.042.576 & Rp 274.678.160 & Rp (26.321.840) \\
\hline \multirow{2}{*}{$\begin{array}{l}\text { Improving } \\
\text { worker quality }\end{array}$} & \multirow{2}{*}{ Rp 5.000.000 } & \multirow{2}{*}{ Rp 306.000.000 } & $6,53 \%$ & 59 & Rp 39.239.737 & Rp 313.917.897 & Rp 7.917.897 \\
\hline & & & $2,10 \%$ & 19 & Rp 12.612.773 & Rp 326.530.670 & Rp 20.530 .670 \\
\hline
\end{tabular}

Rp. 300,000,000, - The next priority improvement is a tool repair program. The board barrier made from hardwood or metal is attached to end of the conveyor belt from the blending stage. The barriers are used to flatten the excessive volume of tobacco during the feed in process. The expectations of installing these barriers are to reduce the impact of the uneven distribution of tobacco volume which can result in defective products. Other tool repairs are by giving markings or signs on the stem, hot air and heater temperature control panel. The marking is expected to reduce error setting machine caused gambling method by operator. The degree of gambling or trial error is expected to be reduced, especially when the initial running process, where product defects are generated produce. For this tool repair program, the budget that must be provided is in the range of Rp. 1,000,000. The last improvement program is by conducting training and briefings on staff and operators. The goal to be achieved from training is improved the work performance from all employees so that it can eliminate or reduce the impact of errors due to a lack The first improvement program that must be done is to invest in a moisture content detection sensor. Moisture sensors are useful for line supervisors to detect changes and variations of moisture content in raw material. Line supervisor can determined setting machine correctly base on those information data. The cost required to purchase moisture sensors is of cooperation between human resources that can cause defective products. Briefing is conducted by the supervisor and production admin to explain information about the working instruction from each run. The costs of training and briefing are in the range of Rp. 5,000,000.

If the solution improvement is implemented consistently and continuously, the number of defects will gradually decrease, which will equally reduce re-feed frequency. The improvements can reduced the number of product defects by $54.37 \%$. A decrease in the number of defects will raise the level of sigma and reduce DPMO. A comparison of sigma and DPMO levels before and after improvement is illustrated in Table 3.

Increasing sigma level and decreasing DPMO certainly has an impact on cost saving. Processing costs per kilo of tobacco are Rp. 825, 1 pack consists of $200 \mathrm{~kg}$ so the processing cost for 1 pack of tobacco is Rp. 660,000. The solution for reducing defect product are proposed as follow: investing moisture sensor, repairing tools and training worker. Each solution has a different investment cost. The solution implemented step by step according to the priority, so that the reduction in defects will also occur gradually. Calculation of improvement costs, cost saving by reduction defect and benefit are presented in Table 4.

In the initial stages of repairs, trhere is no benefit yet from the investment spent into improvement project. Benefits can be obtained after all improvement are made. Based on Table 6 the profits obtained by the company at Rp. 20,530,670. These benefits will increasing if the company continues to make improvements to reach 6 sigma levels.

\section{CONCLUSITION}

From this research, it can be concluded that the high frequency re-feed occured at GLT plant contributed by \% moisture defect. Six sigma method integrated with FMEA are used to reduce re-feed frequency and find out solution improvent. Investing moisture sensor, repairing tools dan training worker are suggested to be solution for improvement. The improvement made increase sigma level to be 3,97 and decrease DPMO to be 6.823 .

\section{REFERENCES}

[1] P. C. Gholap and T. N. Desai, "Reduction of rework the Six Sigma way: case study of an Indian small scale industry,” Int. J. Six Sigma Compet. Advant., vol. 7, no. 1, p. 92, 2012.

[2] S. Hakimi, S. M. Zahraee, and J. Mohd Rohani, "Application of Six Sigma DMAIC methodology in plain yogurt production process," Int. J. Lean Six Sigma, vol. 9, no. 4, pp. 562-578, Oct. 2018.

[3] R. Chase, R. Jacobs, and N. Aquilano, Operations Management - For Competitive Advantage, Eleventh E. McGrawn-Hill Irwin, 2006.

[4] G. Maheshwar, "Application of Six Sigma in a small food production plant of India: a case study,” Int. J. Six Sigma Compet. Advant., vol. 7, no. 2/3/4, p. 168, 2012.

[5] C.-T. Su, T.-L. Chiang, and C.-M. Chang, "Improving service quality by capitalising on an integrated Lean Six Sigma methodology,” Int. J. Six Sigma Compet. Advant., vol. 2, no. 1, p. 1, 2006.

[6] S. Widiyawati and S. Assyahlafi, "Perbaikan produktivitas perusahaan rokok melalui pengendalian kualitas produk dengan metode six sigma,” J. Ind. Eng. Manag., vol. 2, no. 2, p. 32, Dec. 
The $1^{\text {st }}$ International Conference on Business and Management of Technology (IConBMT)

August 3rd 2019, Institut Teknologi Sepuluh Nopember, Surabaya, Indonesia

2017.

[7] T. Z. Santoso, M. Choiri, and N. W. Setyanto, "Peningkatan kualitas rokok Sigaret Kretek Tangan (SKT) dengan metode six sigma studi kasus pada PT. Djarum Kudus-SKT-BL 53,” J. Rekayasa dan Manaj. Sist. Ind., vol. 1, no. 2, pp. 392-403, 2013.
[8] P. S. Pande, R. P. Neuman, and R. R. Cavanagh, The six sigma way. Yogyakarta: Andi, 2002.

[9] C. S. Carlson, Effective FMEAs: Achieving Safe, Reliable, and Economical Products and Processes Using Failure Mode and Effects Analysis. Hoboken, N.J. : John Wiley \& Sons, 2012. 